\title{
Lunar Excavation Experiments in Simulant Soil Test Beds-Revisiting the Surveyor Geotechnical Data
}

\author{
Juan H. Agui and R. Allen Wilkinson
}

ASCE Earth and Space 2012 Conference

April 15-18, 2012 


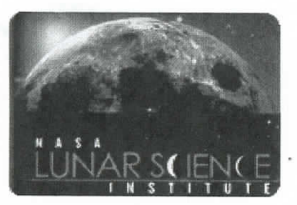

\section{Introduction and Motivation}

- Establishing ISRU technologies on planetary bodies is an important longterm goal of NASA.

- Excavation is a key component of these ISRU processes.

- Lack of flight data relevant to lunar excavation.

- Existing models of the excavation-cutting phenomenon give varying results.

- The lack of predictive models of the dynamic behavior of soils in excavation implements is a major driver for these studies.

- Objective: Need to develop robust models of excavation cutting phenomena that generate predictive capabilities to aid the designer and engineer. 


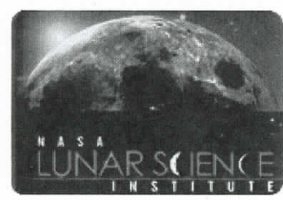

\section{Previous work on Lunar Excavation}

-Surveyor Missions: III (1967) \& VII (1968)

Bearing plate and trenching tests using Soil Mechanics Surface Sampler -Bernold and Rolfsness (1988), Bernold and Sundareswaran (1990), Detwiler et al. (1990), Bernold (1991), Nathan et al. (1992), Boles et al. (1997), Klosky et al. (1996), Berry (2006):

$>\quad$ Tested Various excavation methods under compacted simulated lunar soils.

$>\quad$ Soil properties and soil bed conditions were considered key test conditions.

$>$ Excavating $20 \mathrm{~cm}$ below the lunar surface was determined to be extremely difficult.

-Williams and Boles (1995) and Boles, Scott and Connoly (1997)

- Conducted reduced gravity experiments. Forces did not scale with gravity level.

-Wilkinson (2007)

- Applied classical soil mechanics under lunar regolith conditions.

-Demos: KSC and JSC (Lance) Excavation demos. GRC (Centaur Digger)

-Bucek, Agui, Zeng and Wilkson (2008) Simulated Surveyor tests 

(SMSS)

Surveyor Missions: Seven missions

Assess the lunar surface for safe manned landings.

$>$ Soil property assessment

Landing pad imprints

$\square$ Bearing plate penetrations and trenching tests using SMSS to determine soil properties Surveyor III (1967) \& VII (1968)
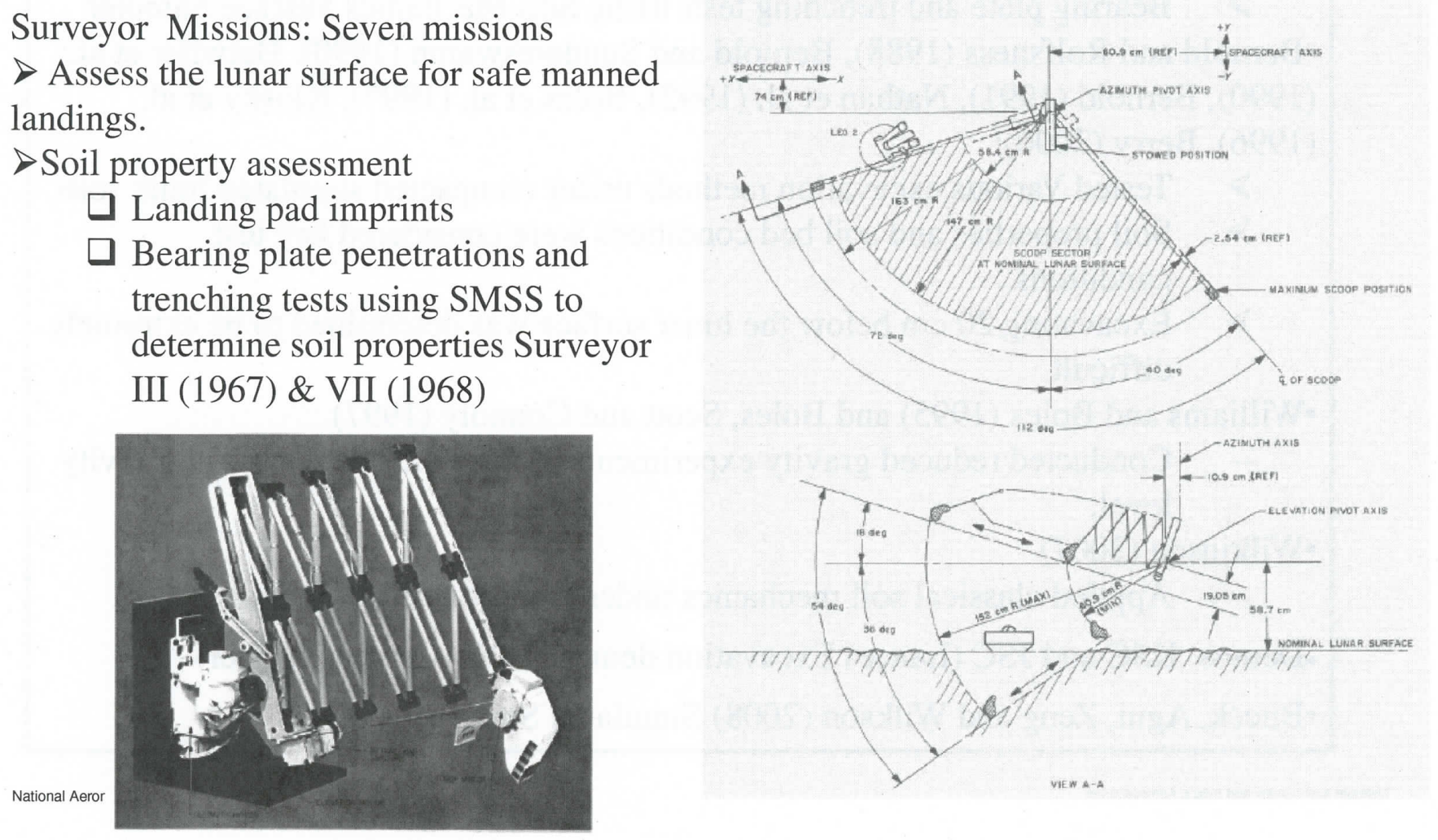

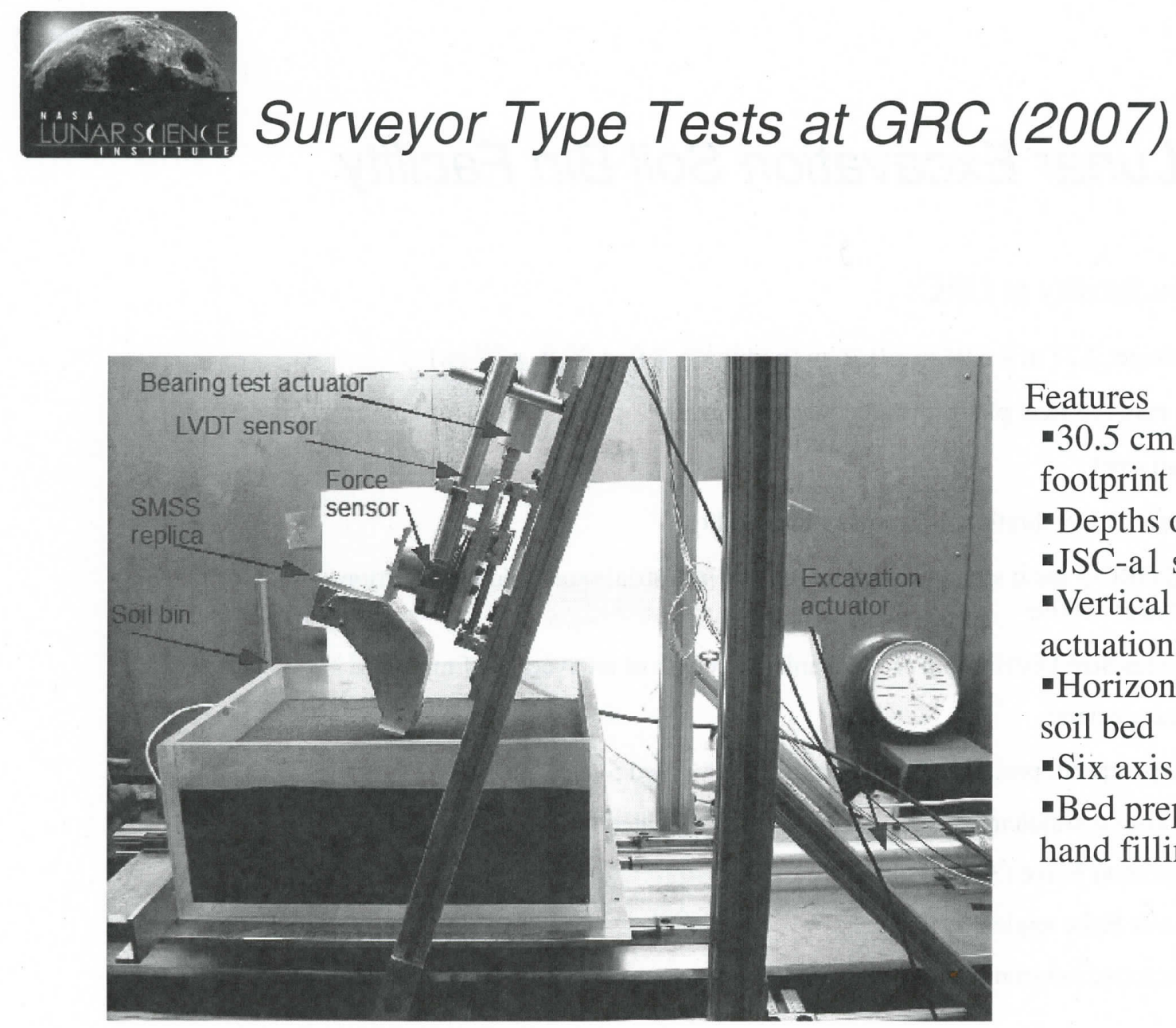

Features

$-30.5 \mathrm{~cm} \times 33.0 \mathrm{~cm}$

footprint

-Depths of 14 and $29.2 \mathrm{~cm}$

- JSC-a1 simulant

- Vertical (inclinable)

actuation

-Horizontal actuation of

soil bed

- Six axis load cell

-Bed prep'd: controlled hand filling.

National Aeronautics and Space Administration 


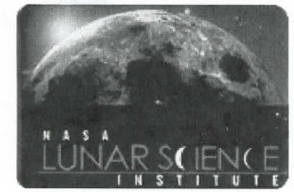

\section{Lunar Excavation Soil Bin Facility}

- New soil bin facility at GRC:

Large volume: $2.27 \mathrm{~m} \times 5.94 \mathrm{~m} \times 0.76 \mathrm{~m}$ (nominally 8 ft. $\times 20 \mathrm{ft} . \times 27 \mathrm{in}$.)

Rests on massive steel platform embedded in concrete (originally used for aircraft engine testing).

$>$ Thick wall steel

Large inertia, low vibration, low noise repeatability.

> 10 MT of GRC-3 lunar simulant soil: mixture of industrial sands and a proportion of silt (He, Zeng, and Wilkinson, 2009)

* Mimics Size Distribution \& Mechanical strength of an average of mare and highland regolith Control parameters:

- Precise speed, position, depth control. (Max speed $5 \mathrm{~m} / \mathrm{s}$ )

* Multi-axis simultaneous motion control (interpolated master-slave capable)

* Maximum Force (3392 N)

* Precise Rake angle.

* Controlled environment. 


\section{Lunar Excavation Soil Bin Facility}

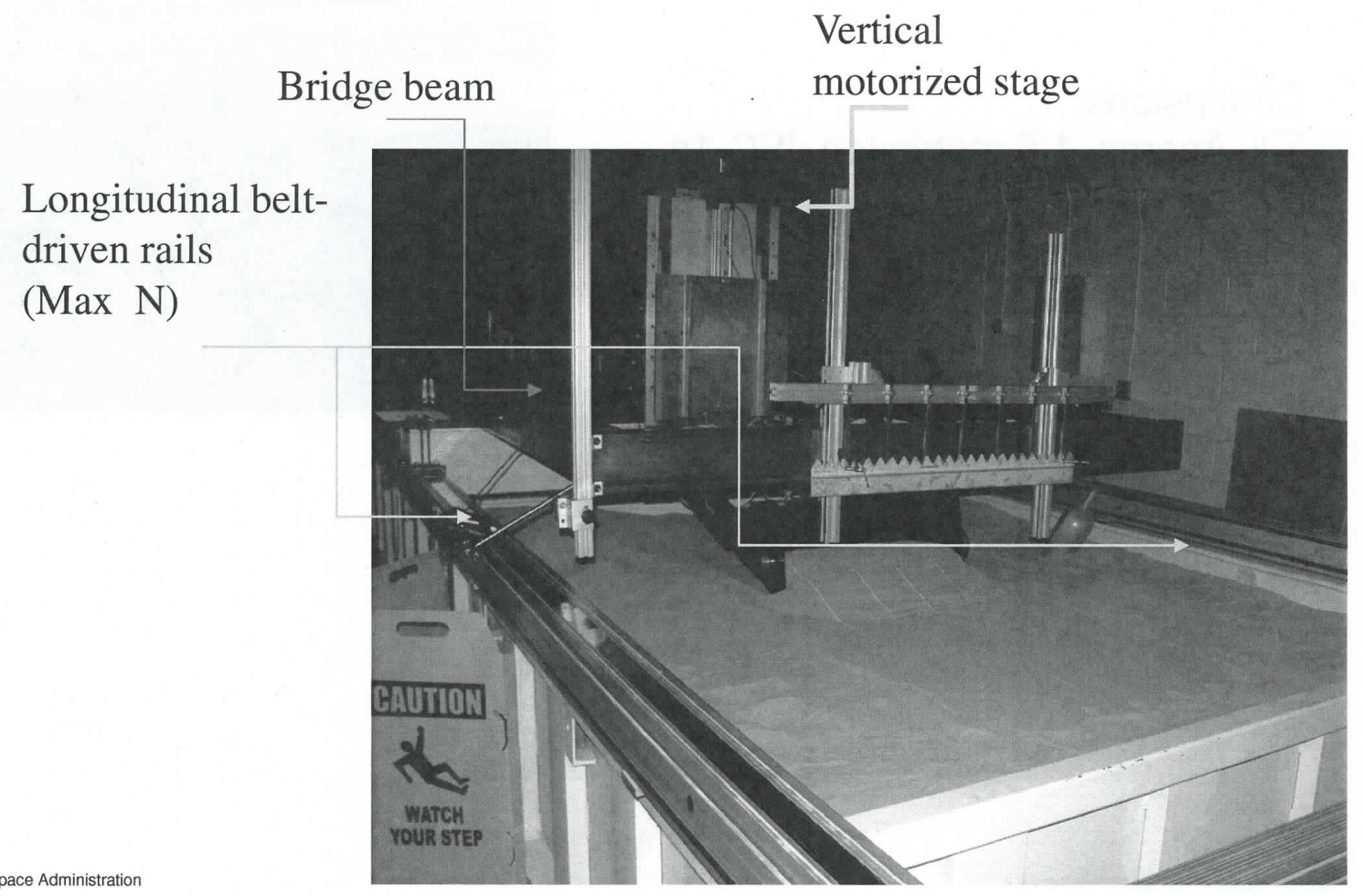


JSC-1a soil bin with Surveyor Scoop

Dimensions:

Fill: Approx. 1.5 metric ton JSC-1a

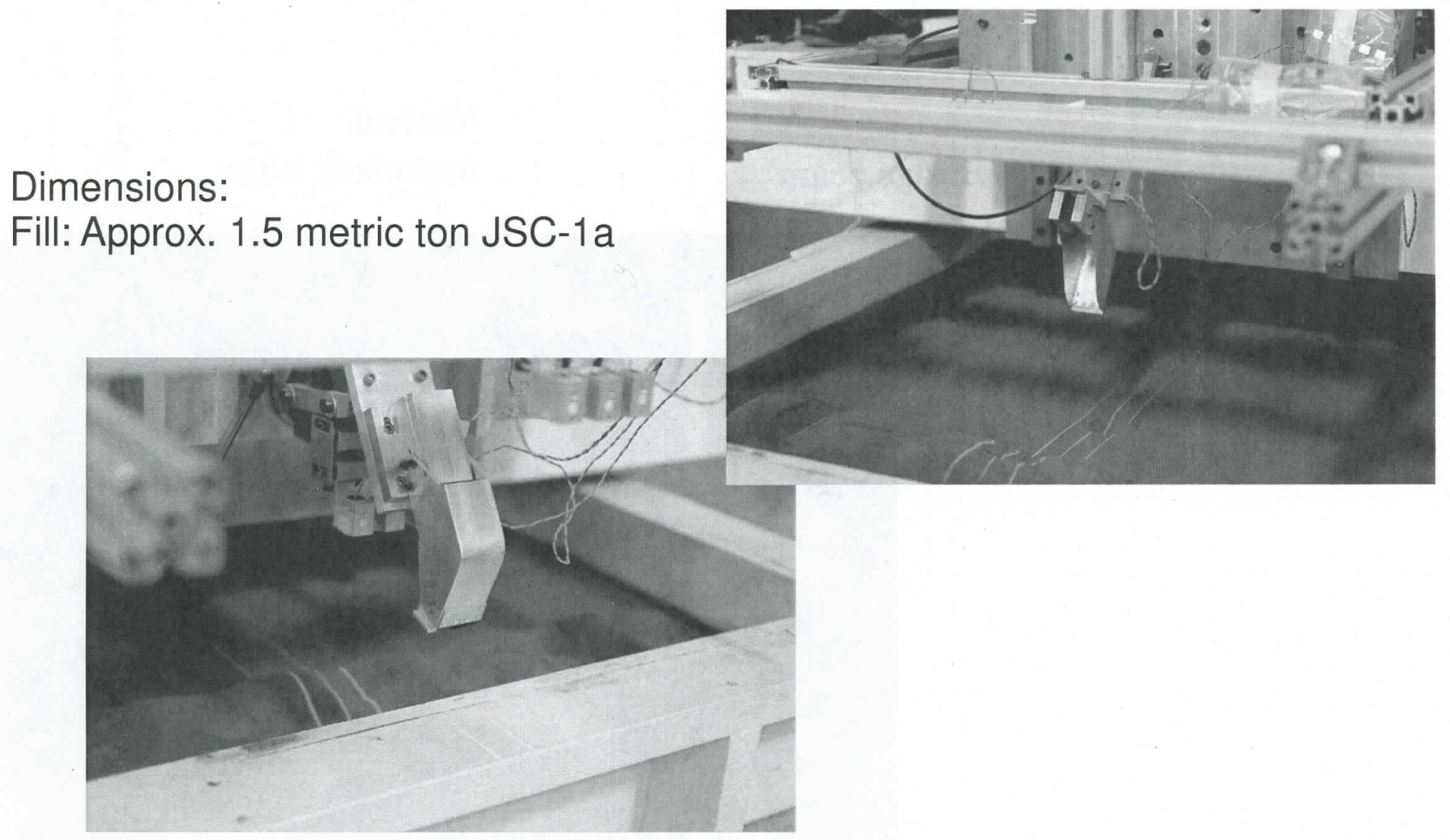




\section{Thate}

- Homogenous bed preps .

- Raking, leveling

- Soil depth ( $10 \mathrm{~cm}$ for laboratory soil bin and $\sim 60 \mathrm{~cm}$ for soil bin facility)

- Surveyor Scoop Bearing Test parameters

- penetration angle $\left(70^{\circ}\right)$

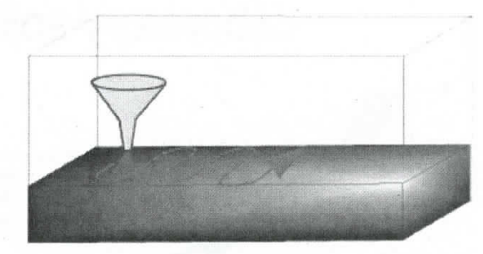

- Stroke speed $(6 \mathrm{~mm} / \mathrm{s})$

- Penetration stroke length ( $50 \mathrm{~mm}$ )

- Excavation Tests procedures

- Rake angle $\left(60^{\circ}\right)$

- Speed $(2 \mathrm{~cm} / \mathrm{s})$

- Travel $(\sim 25 \mathrm{~cm})$

\section{Laboratory soil bin filling}

Soil bin facility preparation

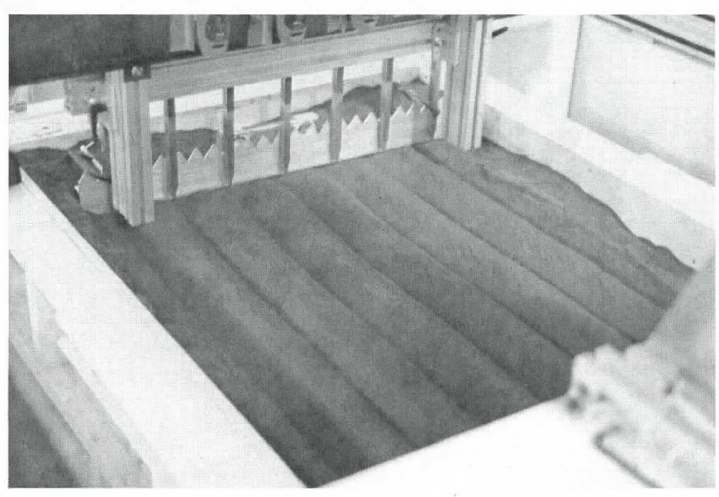

National Aeronautics and Space Administration 


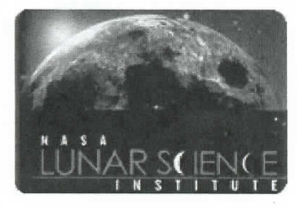

\section{Bearing Tests}

Laboratory soil bin

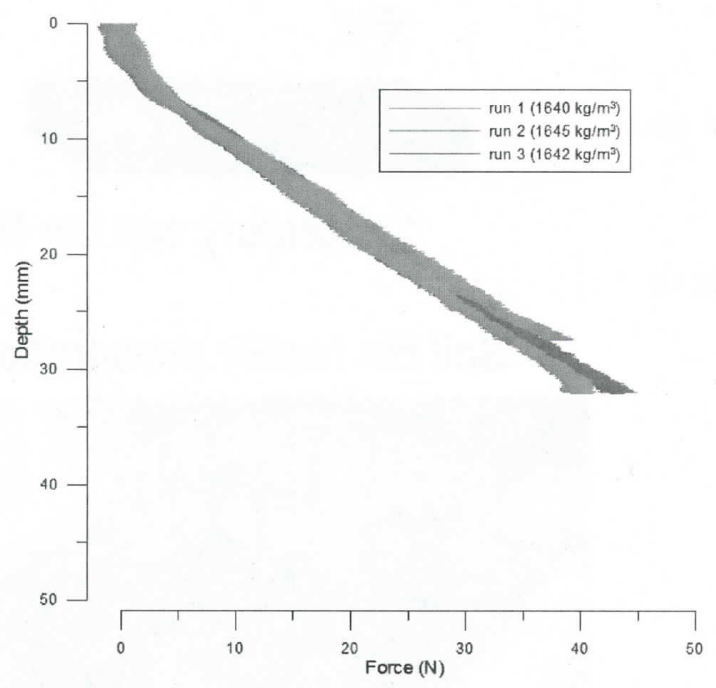

Soil bin facility

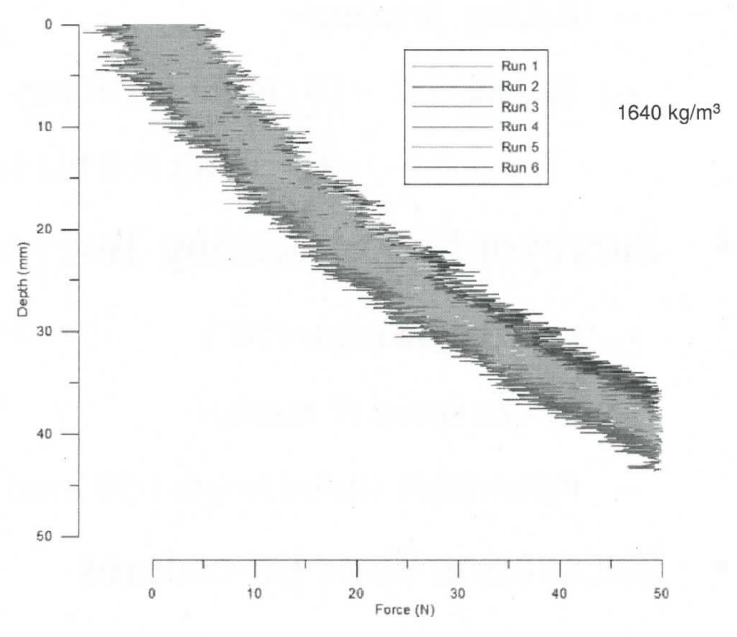




\section{Bearing Tests}

Comparison with Surveyor data

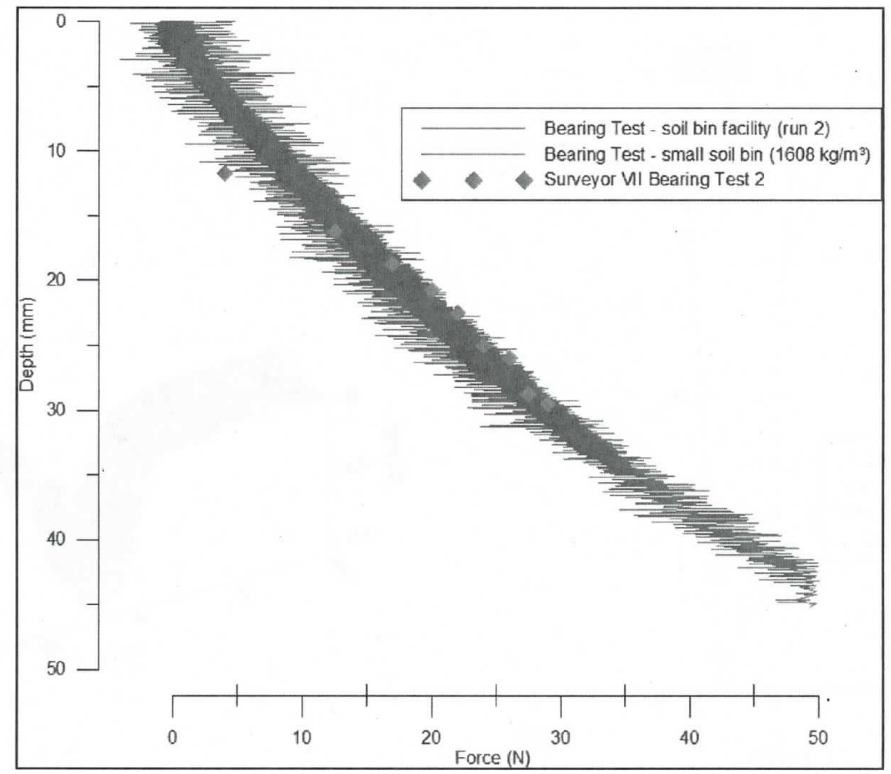




\section{Bearing Test - Surface deformation}
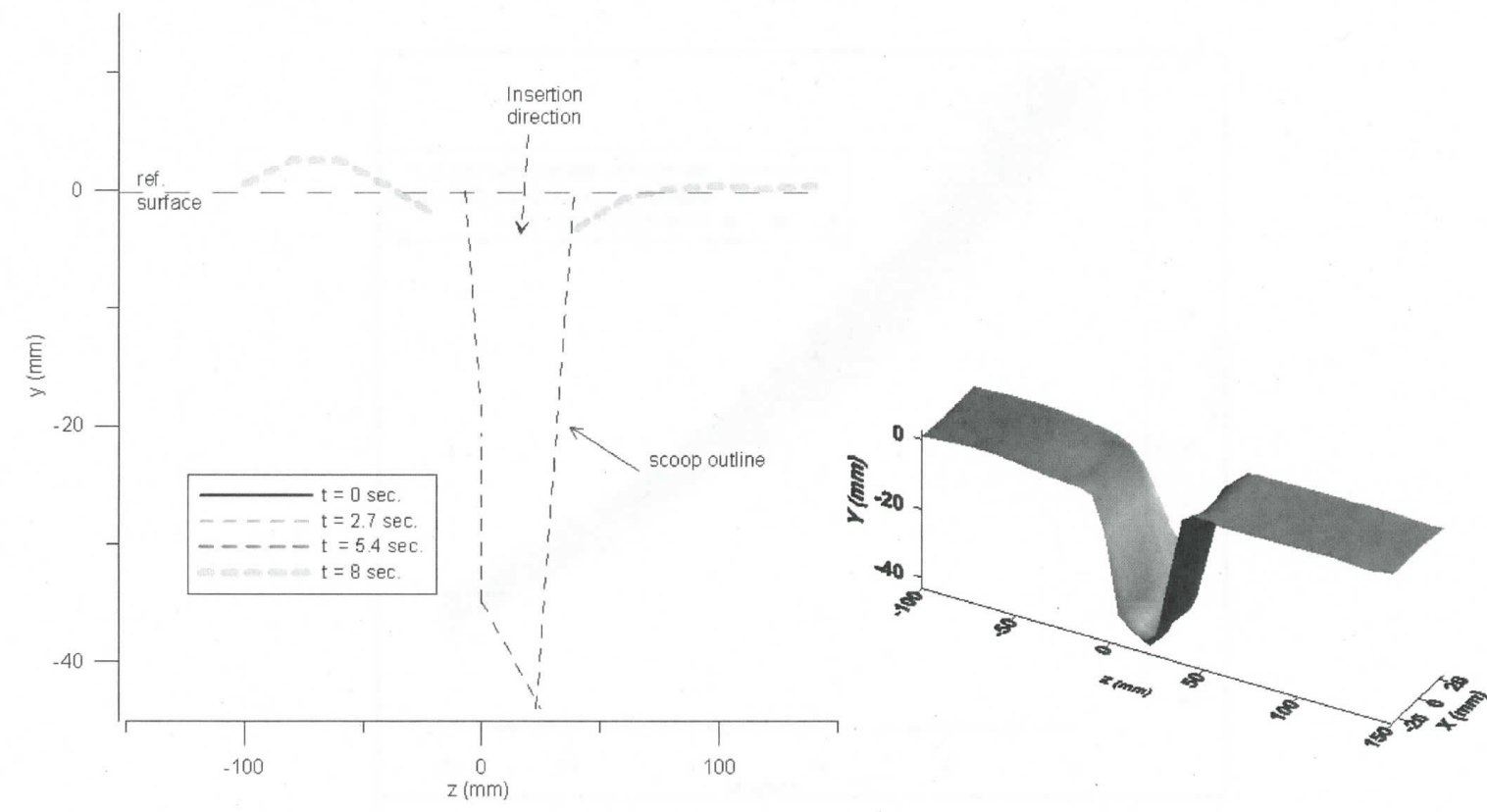

National Aeronautics and Space Administration 


\section{Compacted Soil Bed - Bearing Test
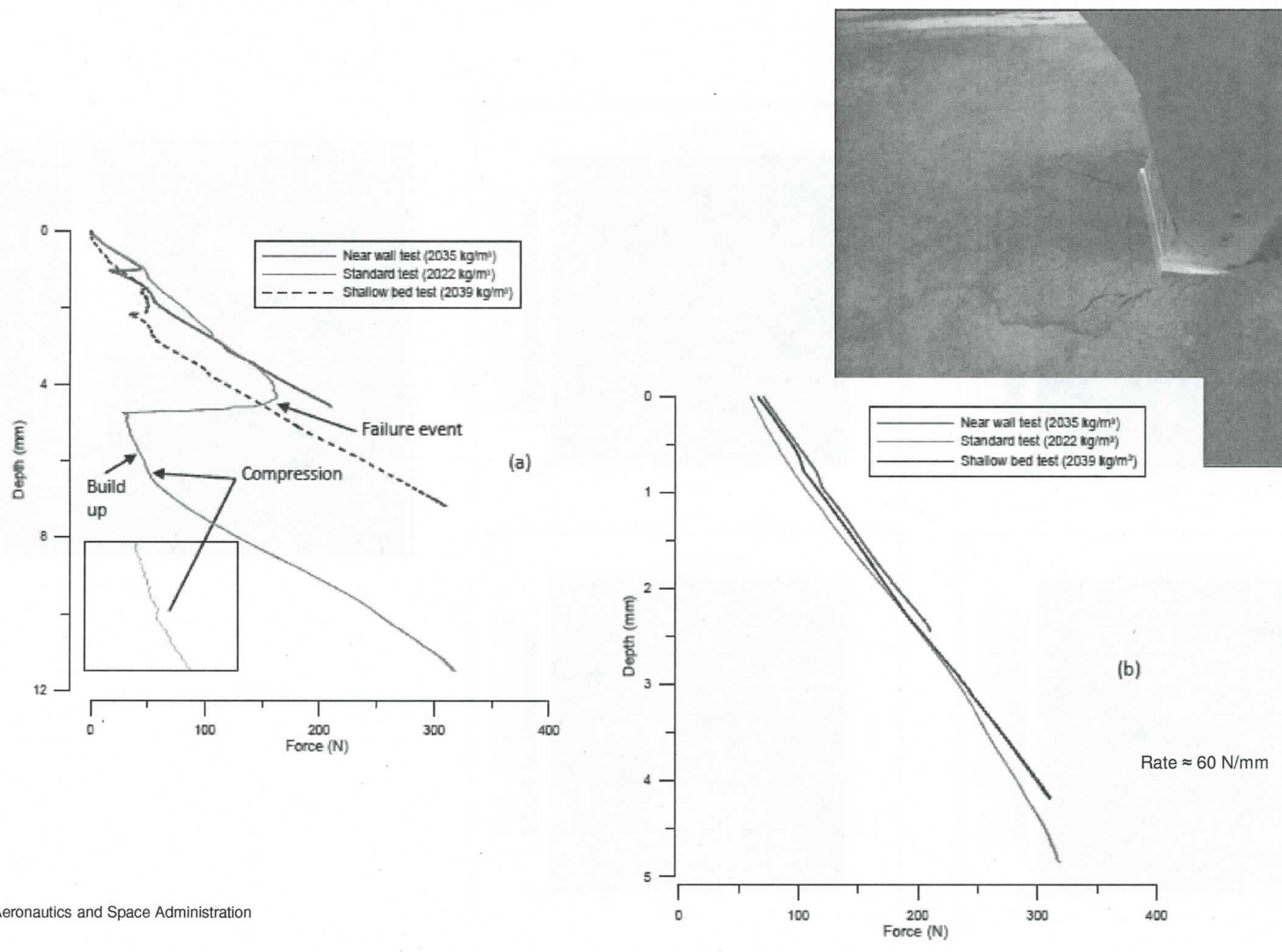

National Aeronautics and Space Administration 


\section{Pressure Mat Measurements}
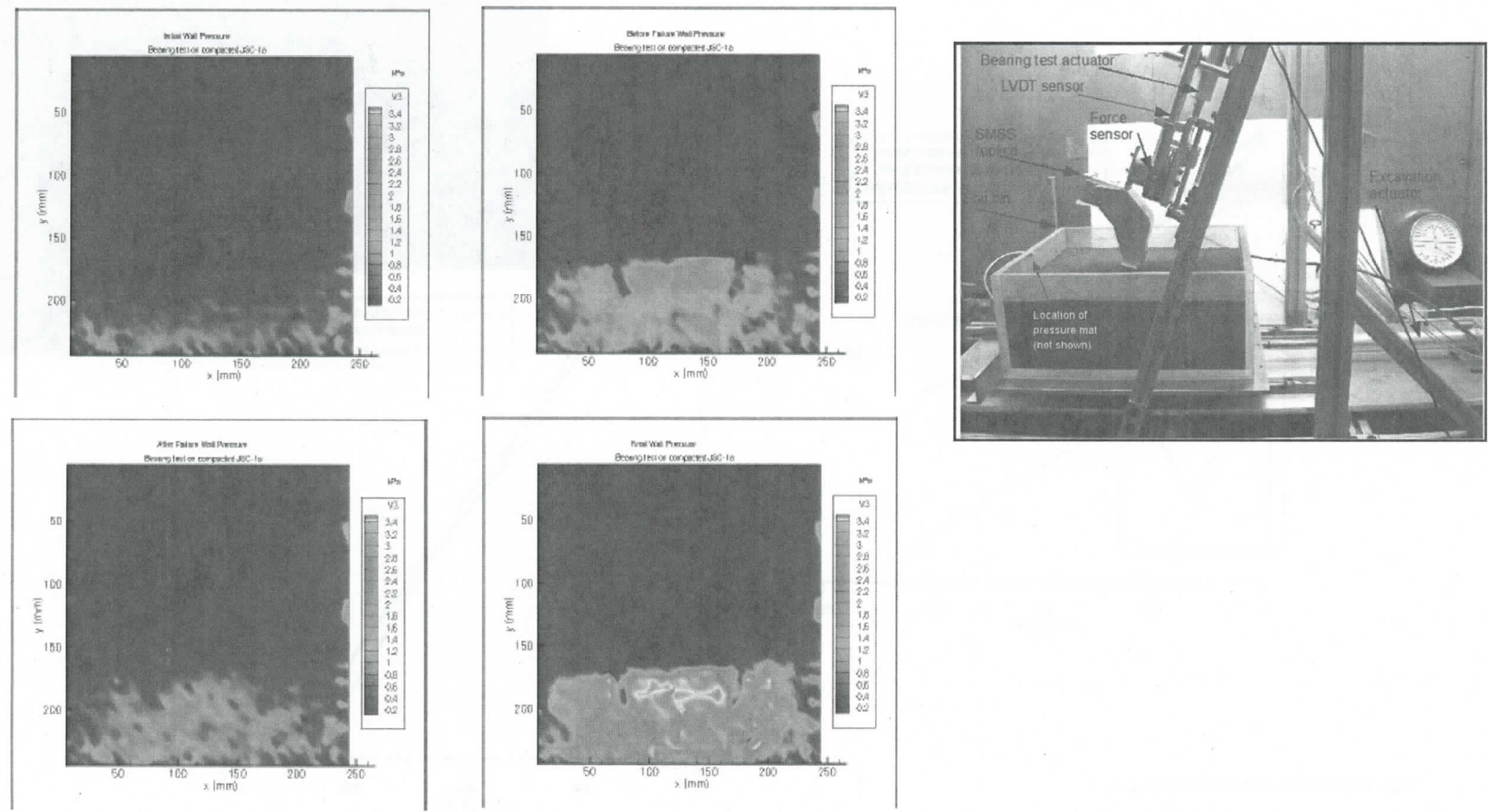


\section{Excavation Tests}
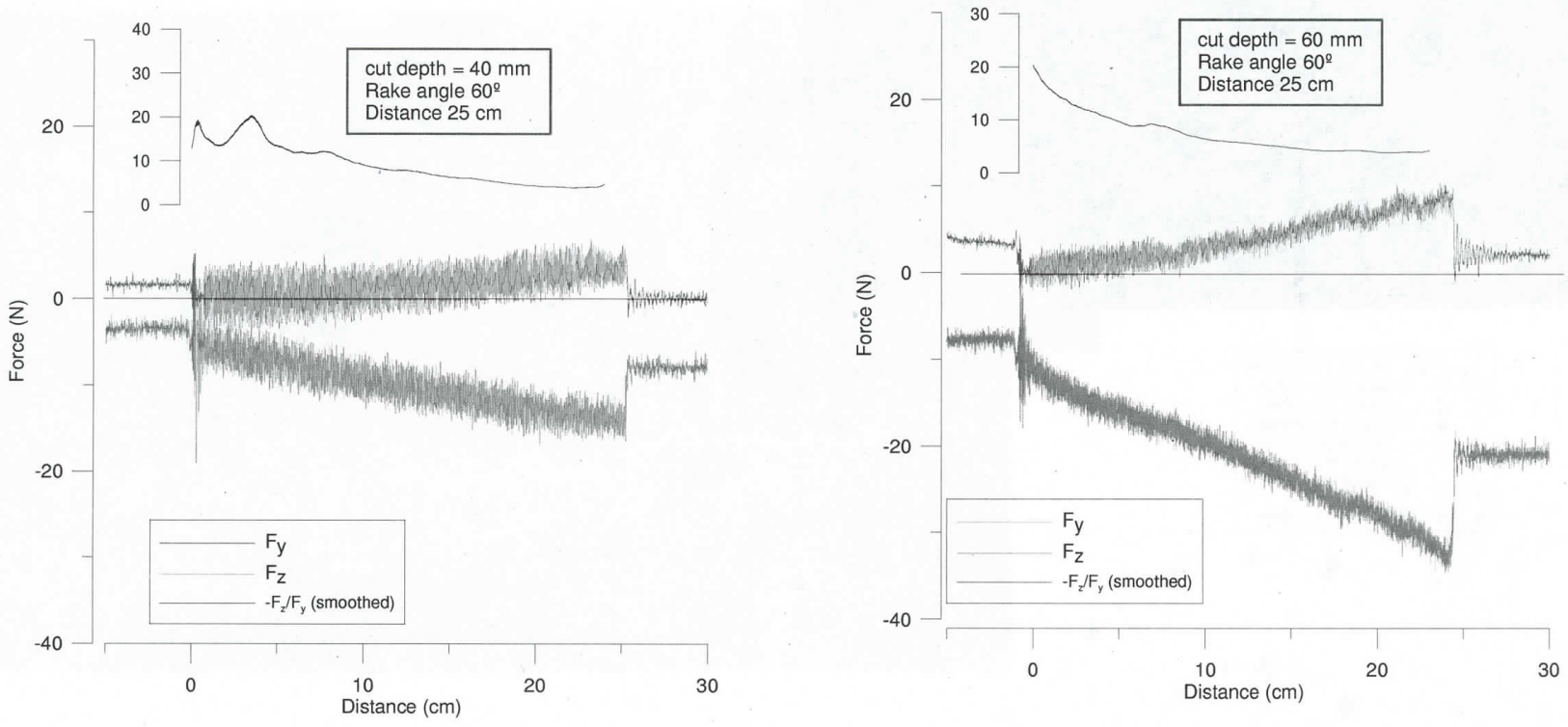

National Aeronautics and Space Administration 


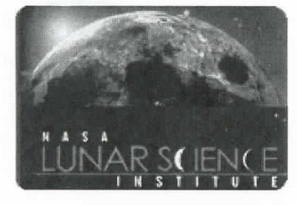

\section{Surface profiling technique}

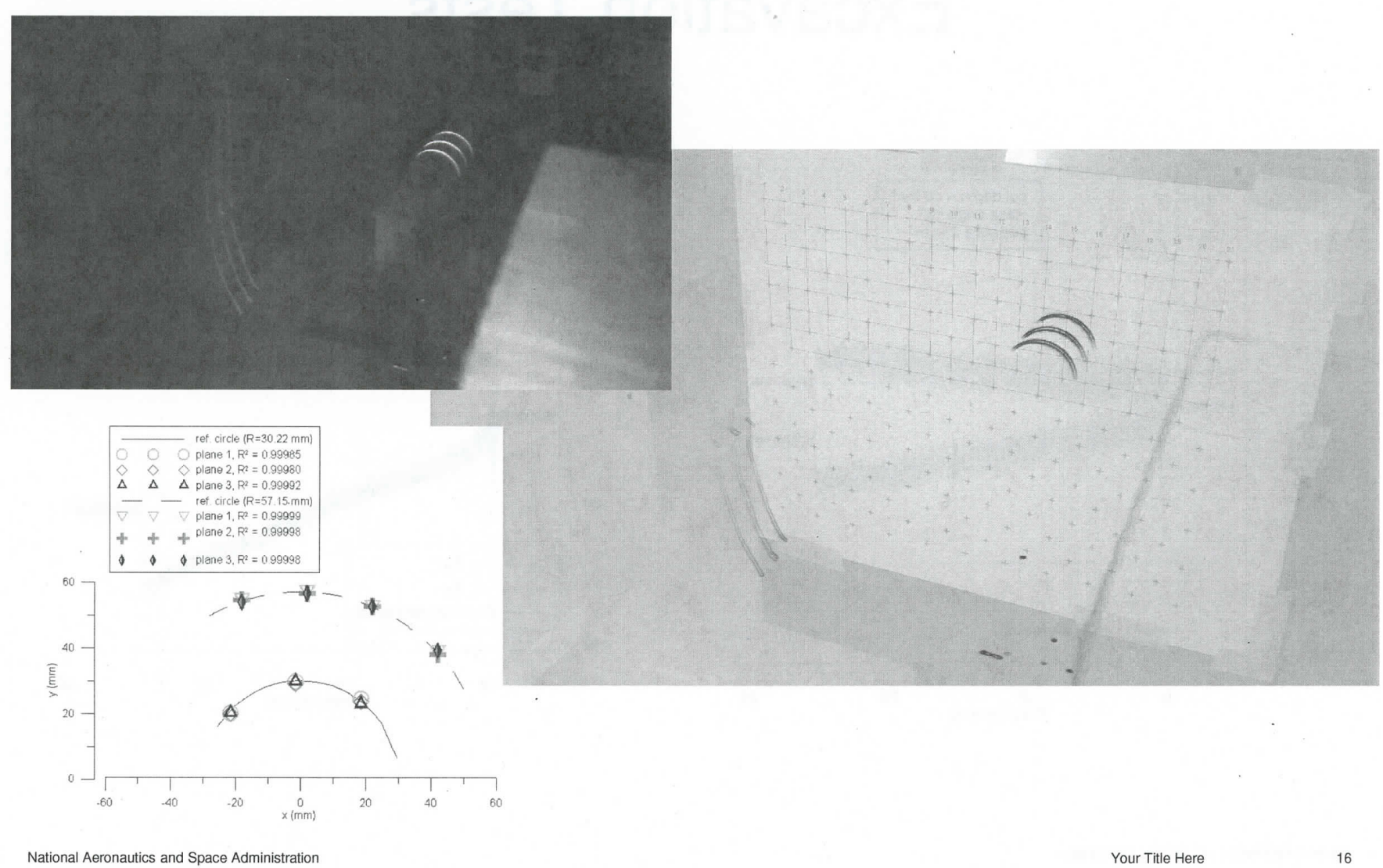




\section{Excavation Tests}
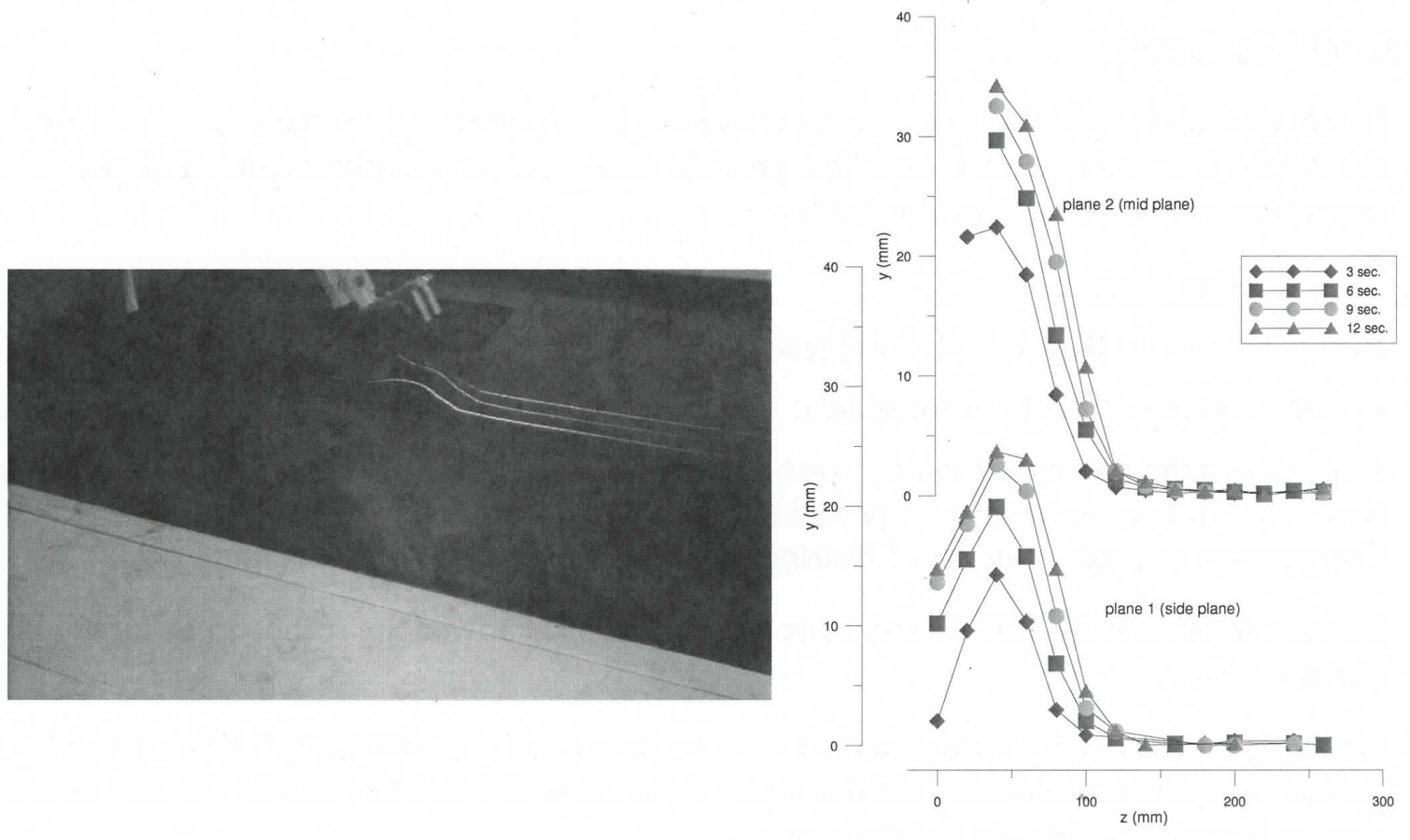

National Aeronautics and Space Administration 


\section{Conclusions}

$\underline{\text { GRC Soil Bin Facility }}$

- Excavation and Surveyor-type bearing tests have been performed in a new lunar soil bin facility at the NASA Glenn Research Center that provide time-resolved measurements of all the forces and torques exerted on the excavator model.

\section{Surveyor Bearing Tests}

- Results similar to Bucek et al. 2008 results.

- Found good repeatability in force data.

- Reproduced the Surveyor Bearing 2 results in loose JSC-1a simulant beds the - Conclude that Surveyor VII bearing tests were probably conducted in low bulk density, or loose, regolith (Note: Comparison with only one set of bearing test data at the Surveyor VII landing site)

- Bearing tests on loose JSC-1a soil beds $\left(\sim 1640 \mathrm{~kg} / \mathrm{m}^{3}\right)$ showed the soil be to be highly inelastically compressible.

- Complex failure events were observed on compacted-soil $\left(\sim 2000 \mathrm{~kg} / \mathrm{m}^{3}\right)$ bearing tests. The failure process was characteristically similar under different wall boundary conditions and resulted in similar force rates after the failure events. 


\section{Conclusions (cont'd)}

\section{Excavation}

- Rapid growth in excavation forces, with the horizontal, or drag, force exceeding the vertical force by several factors. The ratio of drag force to vertical force started out quite high at the start of the excavation and tapered off significantly in the late stage indicating that the mound weight starts to contribute more to the forces in the later stages.

- Surface profiles of the soil-mounding dynamics showed a buildup of the soil layer inside the scoop with avalanching to the sides. In the late stage, the soil mound built up to a maximum height, producing greater avalanching to the sides, and reaching an equilibrium state.

- Sideways material discharge and accumulation of the soil mass in front of the bucket pointed to inefficiencies in bucket excavation operation. 


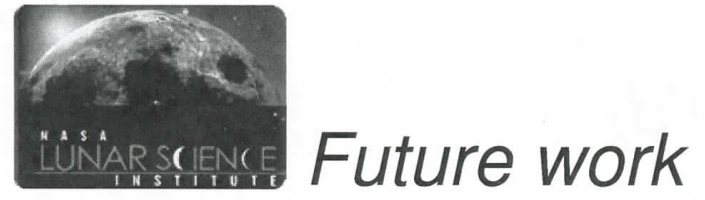

- Develop more complete 3-D surface profiling and analysis

- Develop alternate methods of soil bed preparation (auger tiller) and soil density measurements (nuclear density gauge).

- Use testing techniques on excavators developed for the NASA Human Robotics Systems project. 


\section{Acknowledgements}

Students:

Kenneth Schnautz, U. Indiana, ESMD Student

Alex Kaeden, Michagin Tech, USRP Student

NASA Lunar Science Institute 